Bangladesh J. Bot. 49(1): 85-90 2020 (March)

\title{
EFFECTS OF DIFFERENT FERTILIZER RATIO ON SENESCENCE OF FLAG LEAF IN WINTER WHEAT
}

\author{
YAFEI WANG AND Yan SHI* \\ Dryland-technology Key Laboratory of Shandong Province, College of Agronomy, \\ Qingdao Agricultural University, Qingdao City, China
}

Keywords: Fertilizer ratio, Winter wheat, Flag leaf, Enzyme activity, Senescence

\begin{abstract}
In order to increase the fertilizer use efficiency, the effects of different ratio of slow-release fertilizer, water retention agent and compound fertilizer in wheat production on senescence of flag leaf in winter wheat had been studied. The results showed that, water retaining agent $15 \mathrm{~kg} / \mathrm{ha}$ with slow-release fertilizer 324 $\mathrm{kg} / \mathrm{ha}$ and compound fertilizer $324 \mathrm{~kg} / \mathrm{ha}$ (T2) effectively maintained the activities of superoxide dismutase (SOD), peroxidase (POD), catalase (CAT) activity and soluble protein content in wheat flag leaves after flowering, and reduced the malondialdehyde (MDA) content which could delay the flag leaves senescence and gain high yield in wheat.
\end{abstract}

\section{Introduction}

In agricultural production, fertilizer is one of the important factors in determining yield and quality for crops. However, at present the majority people of China commonly use some wrong fertilization methods, such as chaos and indiscriminate fertilization, so fertilizer utilization rate was only about $30 \%$ ( $\mathrm{Li}$ and Shi 2012). The phenomenon was leading to the increase in fertilizer costs and environmental pollution (Yan and Shi 2008). Faced with this phenomenon, urgently needed a reasonable proportion of fertilizer, it can effectively provide the necessary nutrients for crop growth and development, as well as protect the natural environment (Luo and Shu 2010, Ren and Shi 2018).

Slow-release fertilizer could effectively delay the release of fertilizer nutrients, so the time and intensity of fertilizer nutrient release and crop nutrient absorption law coincides, which to a certain extent, be able to coordinate the needs of plant nutrients, protect and improve crop yields nutrient supply, thus it could reduce fertilizer loss, effectively improve fertilizer utilization efficiency (Li et al. 2008, Li et al. 2013). Water retention agent was a new type of polymer materials, it has a strong ability to absorb water and control action to release retained water, the release of the moisture is relatively consistent to the law of water needed for crop growth and development (Liu et al. 2013). Most of the studies have demonstrated that the use of slow release fertilizer was good for improving soil fertility and growth environment of crop. Studies have shown that the use of slow-release fertilizer could improve the utilization of wheat yield and nitrogen (Yan and Shi 2012). Other studies have shown that the use of water retention agent could improve the moisture and yield of wheat leaf (Zhao et al. 2004). Studies have shown bo-organic fertilizer could improve the soluble sugar content and root activity in wheat root, reduce the content of MDA, and improve the superoxide dismutase and catalase activity in wheat flag leaf, increase the content of proline, delay the senescence of wheat. It has a positive effect on improving wheat yield (Yin and Nang 2013).

There were lots of reports about the application of slow-release fertilizer, water retention agent and fertilizer in wheat production, but the study of the mutual proportions among the three

*Author for correspondence: <1150028572@qq.com>. 
was rarely reported. In the present investigation, the effect of different fertilizer ratio on senescence of flag leaf in winter wheat was studied and the optimum ratios of fertilizer, which provide a theoretical basis for the production practices of wheat was observed.

\section{Materials and Methods}

The experiments were carried out from October 15, 2013 to June, 2014 in the open field in the Qingdao Jiaonan Plots, Shandong Province, China. The experiment material was the wheat variety "Jimai 22". The Conventional Complex Fertilizer (CCF) labelled YAN NONG complex fertilizer whose formula was of 22-8-12 produced by the YAN-NONG-Weifang Agricultural Chain Co., Ltd. was used. The water retaining agent was produced by Anxin Company.

There were 5 treatments with different fertilizer ratios which were CK (Compound fertilizer $934.5 \mathrm{~kg} / \mathrm{ha}$ ), T1 (Water retaining agent $15 \mathrm{~kg} / \mathrm{ha}$ and compound fertilizer $750 \mathrm{~kg} / \mathrm{ha}$ ), T2 (Water retaining agent $15 \mathrm{~kg} / \mathrm{ha}$, controlled-release fertilizer $324 \mathrm{~kg} / \mathrm{ha}$ and compound fertilizer 324 $\mathrm{kg} / \mathrm{ha}$ ) and T3 (Water retaining agent $15 \mathrm{~kg} / \mathrm{ha}$ and controlled-release fertilizer $573 \mathrm{~kg} / \mathrm{ha}$ ) (Table 1). The cost between treatment was same. All fertilizers were applied as basic dose. Randomized block design was maintained in the field with three replication per treatment. The plot size was 20 $\mathrm{m} \times 20 \mathrm{~m}$. No fertilizer and irrigation were applied during the growth and development of wheat. Wheat seed was sown on October 15, 2013 and the seeding quantity was $180 \mathrm{~kg} / \mathrm{ha}$. Protection and other cultural practice were done in the experimental field.

Table 1. Experiment processing settings.

\begin{tabular}{lccc}
\hline Treatment & $\begin{array}{c}\text { Super absorbent resin } \\
(\mathrm{kg} / \mathrm{ha})\end{array}$ & $\begin{array}{c}\text { Slow-release fertilizer } \\
(\mathrm{kg} / \mathrm{ha})\end{array}$ & $\begin{array}{c}\text { Compound fertilizer } \\
(\mathrm{kg} / \mathrm{ha})\end{array}$ \\
\hline CK & 0 & 0 & 934.5 \\
T1 & 15 & 0 & 750 \\
T2 & 15 & 324 & 324 \\
T3 & 15 & 573 & 0 \\
\hline
\end{tabular}

Fresh samples were taken to determine the wheat flag leaf senescence in $7,14,21,28$ days after flowering.

The soluble protein content of flag leaf was determined by Coomassie brilliant blue G-250 staining. The MDA activity of flag leaf was measured by amphi-spectrophotometer. The SOD activity of flag leaf was measured by riboflavin. The POD activity of flag leaf and the CAT activity of flag leaf were measured by the method of $\mathrm{Li}(2000)$. Test data were analysed by the EXCEL.

\section{Results and Discussion}

Fig. 1 shows that different fertilizer ratios could affect the different SOD activity in winter wheat flag leaves. With the increasing the days after winter wheat flower, the SOD activity of leaves showed a downward trend. The highest decrease of the SOD activity of CK was found after 28 days of winter wheat flowering $(61.2 \%)$. The performance of $\mathrm{T} 2$ treatment was the best whose SOD activity decreased only $37.7 \%$ after 28 days of flowering. Fig. 1 also shows that the use of water retaining agent and slow-release fertilizer could effectively reduce the rate of decline in SOD activity of winter wheat flag leaves and effectively inhibit its flag leaf senescence.

Fig. 2 shows the effect of different fertilizer ratios on the CAT activity of winter wheat flag leaf where with the increase of the days after flowering, the CAT activity of winter wheat flag leaf was firstly increased, then a decreasing trend was observed. Compared to other treatments in T2 
treatment CAT activity highly increased and the decline was slow. The CK of control showed a slow rate of increase but decline more rapidly. The overall performance of the trend was CK > T1 $>\mathrm{T} 3>\mathrm{T} 2$. This indicated that the T2 fertilizer ratio effectively improved the CAT activity of winter wheat flag leaves and delayed senescence of flag leaf.

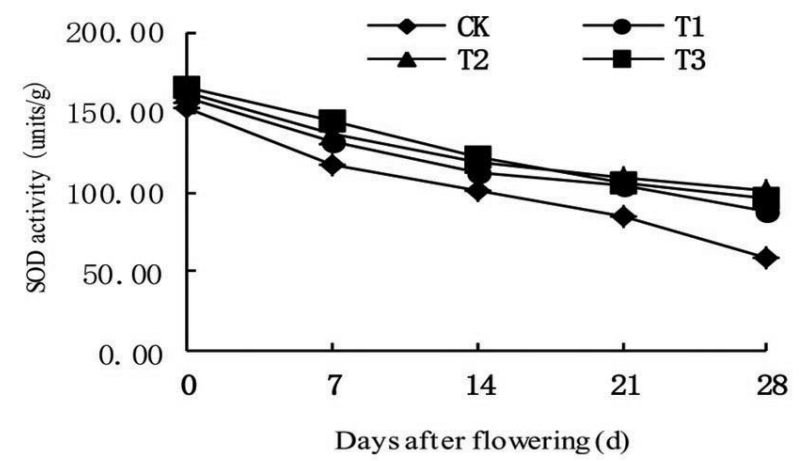

Fig. 1. Effect of different fertilizer ratios on the SOD activity in winter wheat flag leaf.

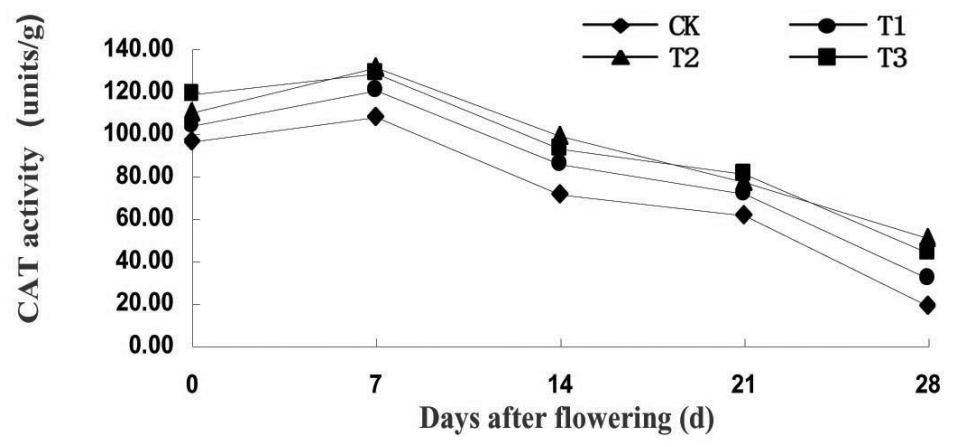

Fig. 2. Effect of different fertilizer ratios on the CAT activity in winter wheat flag leaf.

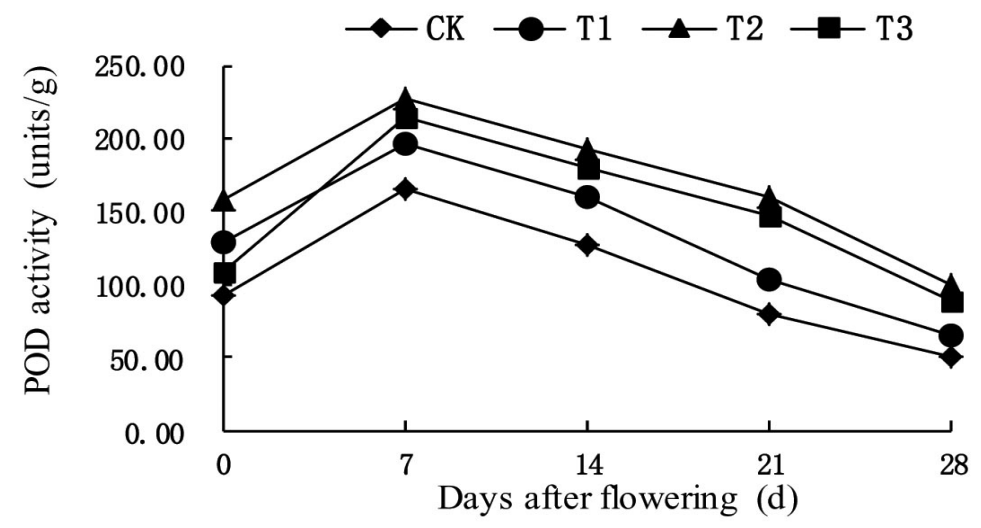

Fig. 3. Effect of different fertilizer ratios on the POD activity in winter wheat flag leaf. 


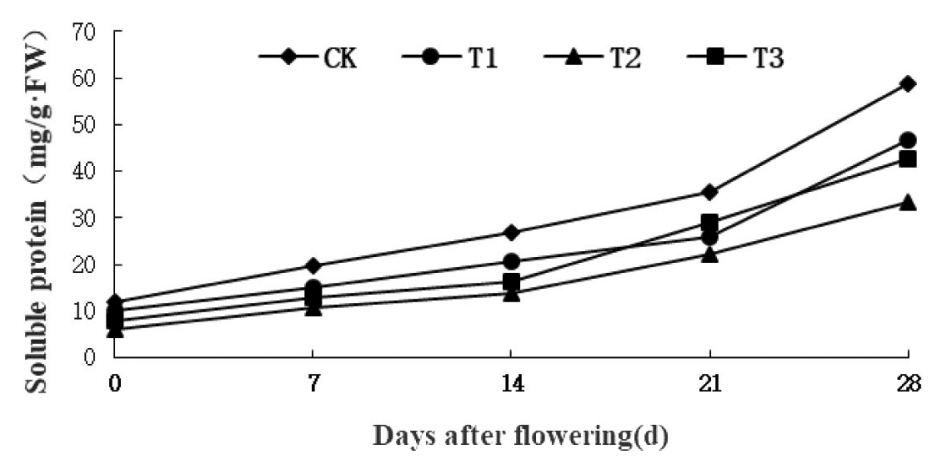

Fig. 4. Effect of different fertilizer ratios on the MDA activity in winter wheat flag leaf.

Fig. 3 reveals that the effects of different fertilizer ratios on POD activity of winter wheat flag leaf was found different. With the increase of the days after flowering the POD activity increased firstly. Then a decreasing trend was found. The POD activity of T2 decreased relatively slow, but the POD activity values were higher than other treatments. In the control group POD activity of CK was minimum. Fig. 3 also shows that the ratio of fertilizer of T2 improved the POD activity of wheat leaves better, which could better reduce the active oxygen damage to the blade, effectively inhibit the senescence of leaf.

As shown in Fig. 4 that with the increase of the days after flowering, the effect of different fertilizer ratios on the MDA activity of winter wheat flag leaf was found different. The MDA activity of CK was growing fast, the MDA actively of but T2 was growing slow and found lowest. The fertilizer ratio of $\mathrm{T} 2$ could effectively reduce the activity of MDA in winter wheat flag leaves, and delay of leaf senescence.

The effect of different fertilizer ratios was found different in protein content of winter wheat flag leaf (Fig. 5). The overall performance was first increased and then decreased. The soluble protein of T2 was found highest and the lowest value was obtained in CK in the 28 days after flowering. The level of soluble protein content was an important sign of wheat leaf senescence, the lower content induced the quick senescence in winter wheat flag leaf.

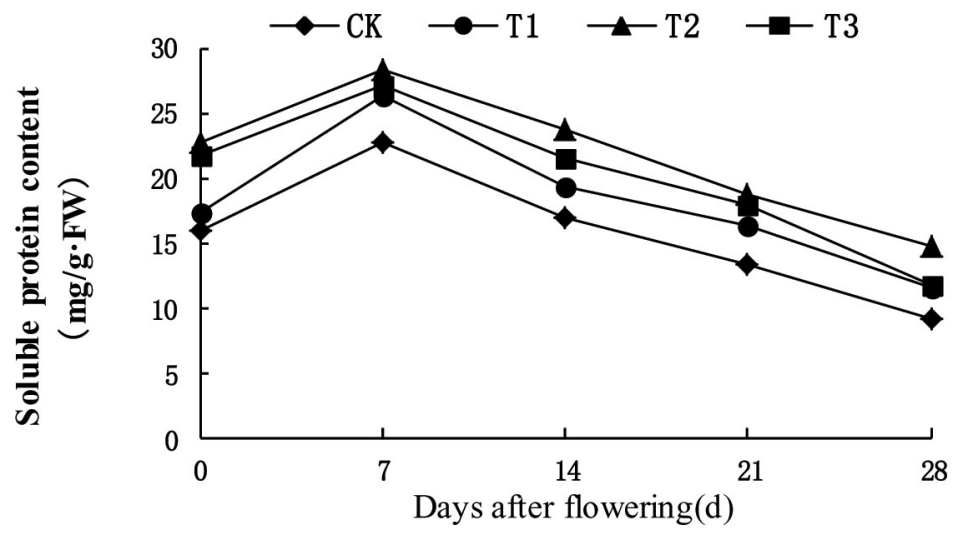

Fig. 5. Effect of different fertilizer ratios on the soluble protein content in winter wheat flag leaf. 
The flag leaf was the most important functional leaves in wheat late stage, their physiological characteristics were closely related to the growth of wheat, which affected the yield and quality of wheat. It was found that with the decrease of soluble protein content, the content of peroxidase activity and MDA increased in the latter part of the growth of wheat. It accelerated aging of the leaves. It was also found that increasing nitrogen application could effectively improve the osmotic adjustment ability of wheat leaves, and delay wheat flag leaf senescence (Hu et al. 2014). Wheat flag leaf cells exist many organic osmolyte substances those have important role in cellpenetrating regulating. The experimental results showed that the fertilizer ratio of $\mathrm{T} 2$ increased soluble protein content of winter wheat flag leaf, decreased protease activity, thereby increasing the osmotic adjustment ability of leaf cells, delayed the wheat leaf senescence.

Plant cells have ROS production and clearance mechanism in dynamic equilibrium state. In the early growth of plants it had very stable balance, but this balance is broken when the plant growth late, it could produce large amounts of reactive oxygen species which damage the plant cells, reactive oxygen species will aggravate membrane lipid peroxidation, damage to the membrane system, accelerated plant senescence. POD, SOD and CAT were important protective enzymes in wheat leaf cells, those were able to effectively remove reactive oxygen species within the cell and thus serve to maintain intracellular reactive oxygen balance and protection cells (Yan and Shi 2013). MDAs is one of the final product of membrane lipid peroxidation, which could be combined with intracellular nucleic acids, proteins, etc. and then loss the activity, thus it could further fail the biofilm and intracellular substances institutions function, eventually leading to the plant cell injury and even death (Zhao et al. 2008). Wheat growth stage controlled-release fertilizer, water retaining agent and reduce soil bulk density, increase soil porosity maintain the good soil permeability and water $\sim$ fertilizer supply in wheat growth stage (Ren et al. 2011). Controlled-release fertilizer could improve soil structure, increase soil microorganisms, improve related activity in wheat after blooming. Fertilizer and water retaining agent could provide water and fertilizer supply for the growth of wheat, effectively improve root activity of wheat (Zheng et al. 2009). It could ensure adequate nutrients for wheat, from vegetative growth to reproductive growth, improve protective enzyme system of cells, reduce membrane system to damage, increase the ability of anti-aging in wheat flag leaves (Kuang et al. 2011).

The experiment showed that the reasonable proportion of water retaining agent, controlledrelease fertilizer and fertilizer could increase SOD, POD, CAT activity and soluble protein content in winter wheat flag leaves after flowering, effectively reduce the activity of MDA, and caused the flag leaf senescence. Now, the reasonable proportion of fertilizer not only can effectively inhibit leaf senescence. But increase photosynthetic capacity and yield of wheat, and also effectively improve the utilization of fertilizer nutrients. It is conducive to save resources and protecting the environment and promoting the development of modern high-efficiency ecological agriculture.

\section{Acknowledgements}

Supported by the Program - The National Key Research and Development Program of China (2016YFD0300400) and Shandong Modern Agricultural Technology \& Industry System cultivation and soil fertilizer and Major application technology innovation projects in Shandong Province.

\section{Reference}

Hu Z, Yang J, Yan L and Shi Y 2014. Effects of super absorbent resin on soil characteristics in dry-land wheat. Advance Journal of Food Science and Technology 6(4): 480-483.

Kuang Y, LI Y and Yu H 2011. Effect of nitrogen on protective enzyme activities and Lipid peroxidation in triticale genotypes with different N use efficiency. Acta Prataculturae Sinica 20(6): 93-100. 
Li G and Shi Y 2012. The effect of different nitrogen on the nitrogen use efficiency and quality of wheat for straw returning. Energy Education Science and Technology. Part A. Energy Science and Research 30(SI -2): 463-468.

Li G, Yang J and Yan L 2013. The effects of controlled release fertilizer and conventional complex fertilizer on the dry matter accumulation and the yield in winter wheat. Research Journal of Applied Sciences: Engineering and Technology 5(7): 2724-2728.

Li H 2000. Plant physiology and biochemistry experimental principles and techniques, Bei Jing: Higher Education Press.

Li W, Chen C and Huang D 2008. New studies trend and prospect on slow or controlled release fertilizer. Research of Soil and Water Conservation 15(6): 263-266.

Liu D and Shi Y 2013. Effects of controlled release fertilizer on the flag leaves senescence in dry-land wheat. Advance Journal of Food Science and Technology 5(5): 557-560.

Luo B and Shu W 2010. Present situation of research and prospect for slowly controlling-releasing fertilizer in China. Chemical Fertilizer Design 48(6): 58-60.

Ren G, Liu X and Shi Y 2011.The high-effective technology for wheat production in dry land .Proceedings 2011 International Conference on materials for Renewable Energy \& Environment, IEEE Catalogue Number:CFP1165N-ART 5(3): 1907-1911.

Ren GX and Shi Y 2018. Correlation between glycosides leaves and agronomic traits of Stevia rebaudina bertoni. Bangladesh J. Bot. 47(2): 337-342.

Yan L and Shi Y 2013. Effects of super absorbent resin on leaf water use efficiency and yield in dry-land wheat. Advance Journal of Food Science and Technology 5(06): 661-664.

Yan L, Shi Y 2012. Effect of different blending fertilizer on root growth and senescence in wheat proceedings 2012 International Conference on Materials for Renewable Energy and Environment. Science Technology Publishing, USA, pp. 1046-1049.

Yan X, Jin J and He P 2008. Recent advances in technology of increasing fertilizer use efficiency. Scientia Agricultura Sinica 41(2): 450-459.

Yin D, Wang Y 2013. Effects of biological organic fertilizer on senescence of flag leaf and roots in wheat. Journal of Qingdao Agricultural University (Natural Science) 30(3):179 -183.

Zhao C, Ma D, Wang Y and Lin Q 2008. Effects of nitrogen application rate and post-anthesis soil moisture content on the flag leaf senescence and kernel weight of wheat. Chinese Journal of Applied Ecology 19(11): 2388-2393.

Zhao G, He Z, Liu L, Yang Y, Zhang Y and Li Z 2004. Study on the co-enhancing regulating effect of fertilization and watering on the main quality and yield in zhongyou9507 high gluten wheat. Scientia Agricultura Sinica 37(3): 351- 356.

Zheng W, Zhang J and Liu Y 2009. Physiological effects of ploughing corn straw under soil on flag-leaf resistance of winter wheat under lowly applying fertilizer condition. Acta Ecologica Sinica 29(9): 49674974. 